\title{
Anti-Obesity Effect of Panax Ginseng in Animal Models: Study Protocol for a Systematic Review and Meta-Analysis
}

\author{
Jae-Heung Cho, Koh-Woon Kim, Hye-Sung Park, Ye-Ji Yoon, Mi-Yeon Song \\ Department of Korean Rehabilitation Medicine, College of Korean Medicine, Kyung Hee University
}

Received: May 9, 2017

Revised: June 2, 2017

Accepted: June 3, 2017
Recently the global epidemic problem of obesity has stimulated intense interest in the study of physiological mechanisms using animal models as a way to gain crucial data required for translation to human studies. Panax ginseng has been reported to have anti-obesity or antidiabetic effects in many animal studies; however, there have been few studies investigating human obesity. Herein, we will assess and examine the evidence supporting the anti-obesity effect of Panax ginseng in animal models with respect to anthropometric and metabolic outcomes. We will include controlled, comparative studies assessing the effect of Panax ginseng in preclinical studies of obesity. Panax ginseng will be administered during or following the induction of experimental obesity. The primary outcome measure will be anthropometric assessment and the secondary outcome measures will include adipose tissue weight, total amount of food consumed and metabolic parameters. We will search MEDLINE, Embase, PubMed, Web of Science, and Scopus without language, publication date, or other restrictions. Ethical approval will not be necessary as the data collected in this study will not be individual patient data, consequently there will be no concerns about violations of privacy. After finishing the whole procedure, the results will be disseminated by publication in a peer-reviewed journal or presented at a relevant conference. This protocol has been registered on the Collaborative Approach to Meta-Analysis and Review of Animal Data from Experimental Studies (CAMARADES) website (http://www.camarades.info).

Key Words: Obesity, Panax, Animal experimentation, Study protocol, Systematic review

\section{Introduction}

The American Medical Association announced its decision to officially classify obesity as a disease in June $2013^{1,2)}$. Obesity is increasingly considered a human health priority ${ }^{3)}$ and a critical health issue requiring both prevention and treatment ${ }^{4,5)}$. These global epidemic problems have stimulated intense interest in the study of physiological mechanisms regulating the balance between energy intake and energy expenditure. Recent research trends in gene targeting and related technologies using animal models have been crucial for evaluating features of human obesity and are being developed in the quest for novel interventions ${ }^{6,77}$.

Panax ginseng, the Greek word "panax" means "cure-all", has several pharmacological and physiological effects that are gradually being discovered. These include beneficial effects on cancer, hypertension, diabetes, and nociception, as well as reported improvements in weak body conditions ${ }^{8,9)}$. It has also been reported to have anti-obesity or antidiabetic effects ${ }^{10-12)}$.

Previous studies have reported various mechanisms for the anti-obesity effect in animal models. These mechanisms include the reduction of intestinal absorption of dietary fat via inhibition of pancreatic lipase activity ${ }^{13)}$, regulation of hypothalamic expression of orexigenic neuropeptide $\mathrm{Y}$ and anorexigenic cholecystokinin ${ }^{14,15)}$, facilitation of lipoprotein lipase, and regulation of peroxisome proliferator-activated receptor $-\gamma$ and adenosine monophosphate-activated protein kinase signaling ${ }^{16,17)}$. 
However, the complicated relationship between Panax ginseng and its anti-obesity effects has not yet been clearly defined under in vivo conditions ${ }^{18)}$. Although Panax ginseng and its components have been shown to exert anti-obesity effects via the modulation of physiological lipid metabolism in vivo or via intracellular signaling in numerous preclinical studies, the results are far from conclusive. Therefore, a systemic review and, if possible, meta-analysis are necessary to more fully examine the anti-obesity effects of ginseng in animal models. To the best of our knowledge, no systematic review or meta-analysis has reported critical evidence regarding the potential benefits of ginseng in animal models of obesity. Based on this study, we will assess and examine the evidence supporting the anti-obesity effect of Panax ginseng in animal models on anthropometric and metabolic outcomes.

\section{Methods}

This protocol was drafted through the recommendations for reporting of systematic reviews and metaanalyses of animal experiments and the Collaborative Approach to Meta-Analysis and Review of Animal Data from Experimental Studies (CAMARADES) guidelines ${ }^{19-21)}$. However, as protocols for systematic review of animal studies are not currently accepted in the International Prospective Register of Systematic Reviews (PROSPERO), this protocol has been registered on the CAMARADES website (http://www.camarades.info).

\section{Types of studies}

We included controlled comparative studies (randomized, quasi-randomized, and nonrandomized) assessing the effect of Panax ginseng in preclinical models of obesity. All study designed for humans, such as randomized controlled studies, case studies, and cohort studies, were excluded. There were no language, publi- cation date or publication status restrictions.

\section{Preclinical animal models}

Genetic, physiological, epigenetic and environmental animal models of obesity will be included in this study ${ }^{6,22-24)}$. Each of these models mimics at least part of the diverse pathophysiological aspects of obesity ${ }^{25}$. Table 1 presents the major animal models of obesity that are induced by several experimental methods ${ }^{7)}$. For our proposed future clinical trials focused on adult obesity, neonatal animal models of obesity will be excluded due to the existence of possible differences in the underlying mechanisms and the response to a specific treatment between the two groups. The comparison group will include healthy, sham-controlled animals or animals from studies that have had obesity induced preclinically but have not undergone any intervention.

\section{Types of interventions}

The preclinical intervention group will include animals from the studies that investigated the anti-obesity effect of Panax ginseng. Although there are numerous variants of ginseng that contain many of the same compounds and medicinal properties, we will mainly focus on Panax ginseng C.A. Meyer (Korean ginseng). Other types of ginseng, such as Panax quinquefolius (American ginseng), Panax japonicas, Panax notoginseng and Panax trifolius will be excluded. Studies using roots of Panax ginseng will be included and using berries or leaves will be excluded. Only oral administrations of ginseng will be included, while administration by other routes, such as intravenous, intramuscular, and intraperitoneal injection will be excluded. And also, studies using only individual substance extracted from ginseng, such as ginsenosides or compound $\mathrm{K}$, will be also excluded. Most processing or extracting method commonly used in clinical practice, such as white ginseng, red ginseng, fermented red 
Table 1. Examples of Animal Models of Obesity

\begin{tabular}{|c|c|c|}
\hline Feature & Model name & Mutation \\
\hline \multirow[t]{6}{*}{ Leptin regulating model } & ob/ob mouse & Lep $^{\mathrm{ob}} /$ Lep $^{\mathrm{ob}}$ (leptin deficiency) \\
\hline & $\mathrm{db} / \mathrm{db}$ mouse & Lep $^{\mathrm{db}} /$ Lep $^{\mathrm{db}}$ (leptin receptor) \\
\hline & s/s mouse & Disrupted STAT3 signal of leptin receptor \\
\hline & Zucker rat & Mutated leptin receptor (fa/fa) \\
\hline & Koletsky rat & Mutated leptin receptor (null mutation) \\
\hline & ZDF rat & Mutated leptin receptor (fa/fa) \\
\hline \multirow[t]{8}{*}{ Diet-induced models } & Diet induced obese rat & Polygenic \\
\hline & Cafeteria diet-induced obesity & Polygenic \\
\hline & High-fat diet-induced obesity & Polygenic \\
\hline & New Zealand obese mouse & Polygenic \\
\hline & Age-related obesity in mice & Polygenic \\
\hline & Age-related obesity in macaques & Polygenic \\
\hline & Maternal overfeeding and exposure to high fat diets & Polygenic \\
\hline & Early postnatal overfeeding induced obesity; rearing in small litters & Polygenic \\
\hline \multirow[t]{5}{*}{ Surgical or chemical models } & Lesion of the ventromedial hypothalamus & \\
\hline & Lesion of the hypothalamic paraventricular nucleus & \\
\hline & Lesion of the hypothalamic arcuate nucleus & \\
\hline & Ovariectomy & \\
\hline & Ablation of brown adipose tissue & \\
\hline \multirow[t]{2}{*}{ Seasonal models } & Syrian hamster & \\
\hline & Siberian hamster & \\
\hline \multirow[t]{2}{*}{ Other models } & Lipodystrophy & \\
\hline & $\begin{array}{l}\text { Growth hormone-deficient dwarf rat } \\
\text { Tubby }\end{array}$ & Growth hormone deficiency \\
\hline
\end{tabular}

ginseng, black ginseng, with water extracted, ethanol-extracted, vinegar extracted, powdered and high-pressure extracted will be included. But processing or extracting methods which are not commonly used, like pectin, enzymes and carbon-dioxide extraction will be excluded. Co-intervention studies will be excluded due to risk of contamination; co-administration with other compounds, herb, formula, or non-oral preparations and combination with exercise. To be included in our analysis, Panax ginseng must have been administered during or following the induction of experimental obesity. Experiments using pretreatment with Panax ginseng will be excluded since they are clinically relevant for prevention, but not for treatment. Studies using Panax ginseng combinatorial products or non-oral preparations, for example injected compounds or suppositories, or compounds extracted from Panax ginseng like individual ginsenosides, will be excluded. Studies where the Panax ginseng was given with the expressed intention of worsening rather than improving outcomes will also be excluded.

\section{Types of outcome measures}

\section{1) Primary outcome}

Primary outcome measures will be the anthropometric assessments generally used to evaluate the anti-obesity effect, including body weight and body mass index (BMI) measured at the longest follow-up time after administration of the intervention.

\section{2) Secondary outcomes}

Secondary outcome measures will include adipose tissue weight, total amount of food consumed and metabolic parameters, such as triacylglycerol, high-density lipoprotein, low-density lipoprotein, insulin, glucose, and so forth. In order to be aggregated in the metaanalysis, the exact animal numbers in each group, the 
mean effect size, and the variance of the consequences need to have been reported.

\section{Search methods for identification of studies}

\section{1) Electronic searches}

In consultation with an experienced medical information-scientist or librarian, we will search MEDLINE, Embase, PubMed, Web of Science, and Scopus without language, publication date, or other restrictions. The search strategy will be reviewed by another information specialist using the Peer Review of Electronic Search Strategies (PRESS) template ${ }^{26)}$. Animal filters validated for PubMed/MEDLINE and Embase will be used to enhance the search efficiency with respect to finding all animal studies ${ }^{27,28)}$. Details of the PubMed search strategy developed with guidance from Leenaars et al. ${ }^{29}$ appear in Appendix.

\section{2) Searching other resources}

We will search the grey literature, which are materials and research produced by organizations outside of the traditional commercial or academic publishing and distribution channels, of selected conference websites not covered in the aforementioned databases, as well as the websites of animal research organizations and Google Scholar.

\section{Data Collection and Analysis}

\section{Selection of studies}

Two reviewers will independently review and deter-
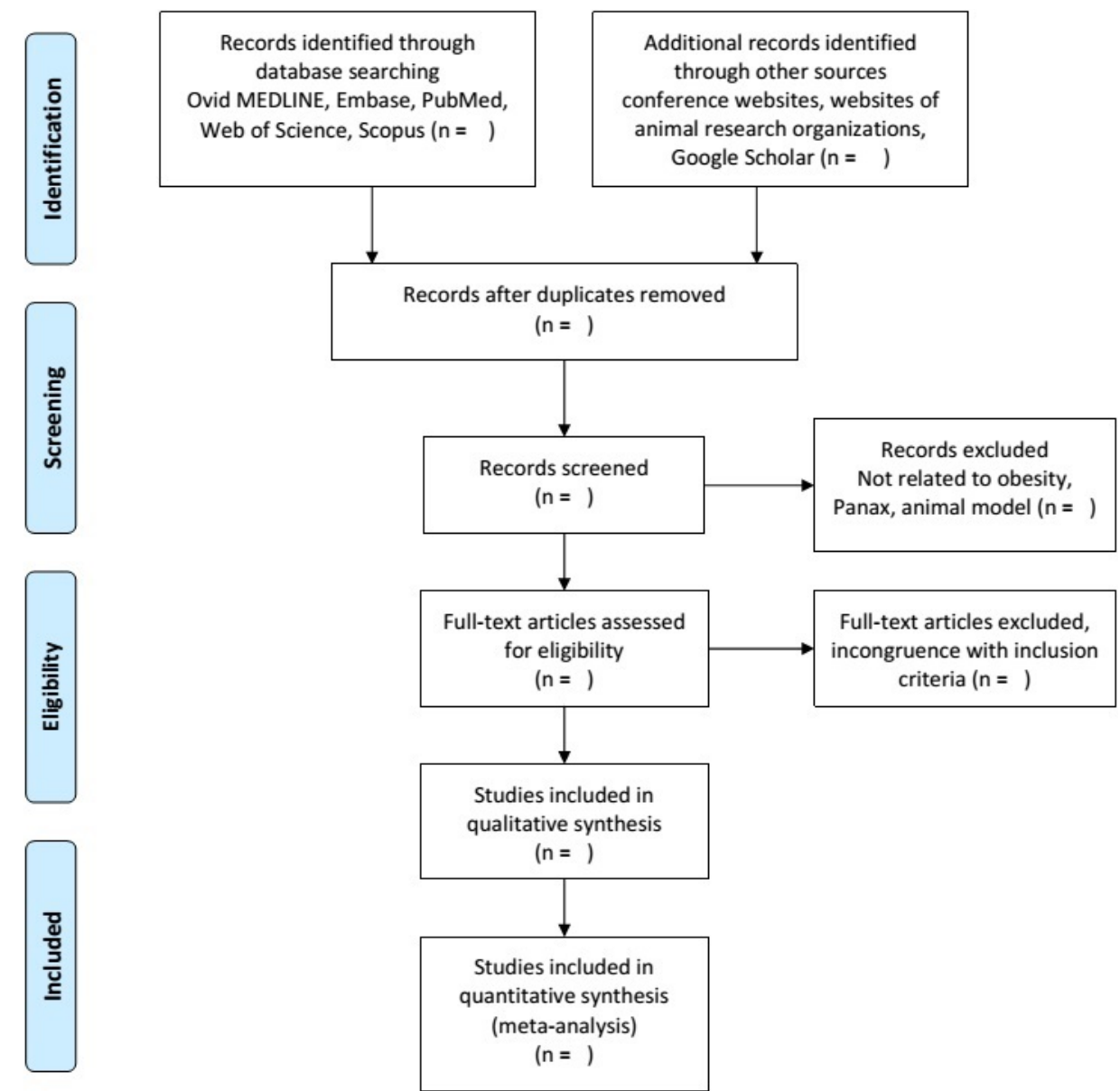

Fig. 1. Flow diagram of the study selection process. 
mine the eligibility of studies. Disagreements between investigators will be resolved by consensus after discussion. Duplicates and non-experimental studies will be removed by screening the titles and abstracts. Reviewers will carefully examine the full text of studies if they are not sure whether the studies meet the inclusion criteria. Studies will be excluded if they involve any unqualified interventions. Study selection is summarized in a PRISMA flow diagram (Fig. 1) $)^{30)}$.

\section{Data extraction and management}

We will extract data from included studies on: 1) study characteristics (study title, journal published, author, publication date); 2) study population (animal type, age, gender, strain, husbandry conditions); 3) type and name of obesity model (leptin regulating model, diet-induced models, surgical or chemical models, seasonal models, others); 4) intervention and comparison (time and route given, description of preparation and suspension of Panax); 5) outcome measures (body weight, BMI, adipose tissue weight, total amount food consumed, metabolic parameters); 6) risk of bias assessments (according to the CAMARADES) $)^{31)}$; and 7) quality of reporting of individual preclinical studies (in accordance with elements of the Animal Research: Reporting of In Vivo Experiments [ARRIVE] guidelines) ${ }^{32)}$. Data will be independently assessed and extracted by two reviewers using standardized extraction forms. Information not available from the script will be requested from the first or corresponding author by email. Extracted data will be reviewed by another researcher, and discrepancies will be adjusted by the arbitrator.

\section{Assessment of risk of bias in included studies}

The methodological quality of individual studies will be assessed according to the Collaborative Approach to CAMARADES guidelines ${ }^{20,33)}$ and the Animal Research: Reporting in Vivo Experiments guidelines ${ }^{32}$. The
CAMARADES guidelines evaluate the following checklist items: publication in a peer-reviewed journal instead of only in abstract form, randomization of treatment, presence of allocation concealment, blinded assessment of outcome, conduct of a pre-experimentation sample size calculation, evidence of animal welfare compliance, statement regarding possible conflict of interest, and completeness of follow-up. The quality scale of each item ranges from 0 to 7 points.

\section{Measures of treatment effect}

For continuous data, the mean difference (MD) will be used to measure treatment effect with $95 \%$ confidence intervals (CIs). For dichotomous data, treatment effects are presented as a risk ratio (RR) with 95\% CIs. Other binary data will be changed into the RR form. Standardized MD will be used with $95 \%$ CIs in cases were the outcome variables have different scales.

\section{Dealing with missing data}

The reviewers will try to obtain significant information through contact with the first or corresponding authors by email if there are missing data that cannot be ignored.

\section{Assessment of heterogeneity and data synthesis}

To determine whether the included studies have sufficient homogeneity to allow for a meta-analysis, we will conduct the analysis of between-study heterogeneity by calculating $\mathrm{I}^{2}$ inconsistency values. Heterogeneity will be defined according to the range of the $\mathrm{I}^{2} ; 0 \%$ to $40 \%$ indicating no important heterogeneity, $40 \%$ to $60 \%$ indicating moderate heterogeneity, $60 \%$ to $90 \%$ indicating substantial heterogeneity, and $>90 \%$ indicating considerable heterogeneity ${ }^{34)}$. These results will be used to determine whether the included studies have sufficient homogeneity to allow for a meta-analysis. In the presence of the heterogeneity of included studies, a 
narrative synthesis will be presented. Otherwise, a metaanalysis will be performed with a fixed-effects or a random-effects model using the Comprehensive MetaAnalysis software, ver. 3.0 (Biostat, Englewood, NJ, USA). Where differences in the change of outcome over time are of interest, we will include these data by calculating the area under the performance-time curve for different cohorts. Using the data extracted regarding mean and variance point estimates, all time points will be used to calculate one overall comparison with standard deviation ${ }^{21}$. Depending on the number of studies available, other subgroup analyses, including dose dependence and animal models and so forth, will be performed.

\section{Assessment of publication bias}

A graphical funnel plot will be used to investigate the presence of publication bias in the studies included in the review ${ }^{35)}$.

\section{Ethics and Dissemination}

Ethical approval will not be necessary, since the data collected in this study will not be individual patient data, and therefore we have no concerns regarding violations of privacy. After finishing the entire procedure, our results will be disseminated as a publication in a peerreviewed journal or presented at a relevant conference.

\section{Discussion}

This systematic review will inform translational and clinical scientists, clinicians, and health regulators regarding existing preclinical evidence relevant to Panax ginseng in animal obesity models. Many experimental studies on the anti-obesity effects of Panax ginseng have already been published; however, no clinical trials designed for human evaluation have been reported yet.
Therefore, a systematic analysis of experimental studies is necessary to evaluate the feasibility prior to future clinical trials. There are several examples that have shown that systematic reviews of preclinical animal studies carried out prior to the start of clinical trials can save resources and can lead to improved safety for participants in clinical trials ${ }^{36,37)}$.

Experimental evidence, like clinical evidence, is used to inform decisions about the safety and efficacy of interventions for participants in clinical trials ${ }^{38)}$. Although animal studies can contribute significantly by providing clinical evidence regarding the possible transition from preclinical studies to clinical trials, most preclinical animal studies are not systematically reviewed ${ }^{39,40}$. One unique and typical problem of animal studies is a large amount of heterogeneity between studies ${ }^{41)}$. However, practical methods and guidelines already exist for exploring heterogeneity within meta-analyses of preclinical systematic reviews ${ }^{21)}$. Furthermore, the international community of researchers conducting systematic reviews of preclinical animal studies, such as the CAMARADES and the Systematic Review Centre for Laboratory animal Experimentation (SYRCLE), are encouraging the research community to perform of more high-quality systematic reviews ${ }^{41)}$. With this as our goal, we will investigate the challenges and limitations related to the conduct of these preclinical studies.

\section{Acknowledgements}

The authors would like to thank The Korean Branch of Australasian Cochrane Center for providing advice on how to make search strategies.

\section{References}

1. Pollack A. AMA recognizes obesity as a disease. New York : NY Times. $2013: 18$. 
2. The American Medical Association. AMA adopts new policies on second day of voting at annual meeting. Press Release. 2013; $21: 35$.

3. Gortmaker SL, Swinburn BA, Levy D, Carter R, Mabry PL, Finegood D, et al. Changing the future of obesity: science, policy, and action. Lancet. 2011 ; 378(9793) : 838-47.

4. Nejat EJ, Polotsky AJ, Pal L. Predictors of chronic disease at midlife and beyond: the health risks of obesity. Maturitas. 2010 ; 65(2) : 106-11.

5. Brown WV, Fujioka K, Wilson PWF, Woodworth KA. Obesity: why be concerned? Am J Med. 2009 ; 122(4 Suppl 1) : S4-11.

6. Kaiyala KJ, Schwartz MW. Toward a more complete (and less controversial) understanding of energy expenditure and its role in obesity pathogenesis. Diabetes. $2011 ; 60(1): 17-23$.

7. Lutz TA, Woods SC. Overview of animal models of obesity. Curr Protoc Pharmacol. 2012 ; Chapter 5 : Unit5.61.

8. Rastogi V, Santiago-Moreno J, Doré S. Ginseng: a promising neuroprotective strategy in stroke. Front Cell Neurosci. $2014 ; 8$ : 457.

9. Jung NP, Jin SH. Studies on the physiological and biochemical effects of Korean ginseng. Korean J Ginseng Sci. 1996 ; 20 : 431-71.

10. Han LK, Kimura Y, Kawashima M, Takaku T, Taniyama T, Hayashi $\mathrm{T}$, et al. Anti-obesity effects in rodents of dietary teasaponin, a lipase inhibitor. Int J Obes Relat Metab Disord. $2001 ; 25(10): 1459-64$.

11. Han LK, Zheng YN, Xu BJ, Okuda H, Kimura Y. Saponins from Platycodi Radix ameliorate high fat diet-induced obesity in mice. J Nutr. $2002 ; 132(8): 2241-5$.

12. Xie JT, Zhou YP, Dey L, Attele AS, Wu JA, Gu M, et al. Ginseng berry reduces blood glucose and body weight in $\mathrm{db} / \mathrm{db}$ mice. Phytomedicine. 2002 ; 9(3) : 254-8.

13. Karu N, Reifen R, Kerem Z. Weight gain reduction in mice fed Panax ginseng saponin, a pancreatic lipase inhibitor. J Agric Food Chem. 2007 ; 55(8) : 2824-8.

14. Kim JH, Kang SA, Han SM, Sim I. Comparison of the antiobesity effects of the protopanaxadiol- and protopanaxatriol-type saponins of red ginseng. Phytother Res. 2009; 23(1) : 78-85.

15. Kim JH, Hahm DH, Yang DC, Kim JH, Lee HJ, Shim I. Effect of crude saponin of Korean red ginseng on high-fat diet-induced obesity in the rat. J Pharmacol Sci. 2005 ; 97(1) : 124-31.

16. Hwang JT, Kim SH, Lee MS, Kim SH, Yang HJ, Kim MJ. Anti-obesity effects of ginsenoside Rh2 are associated with the activation of AMPK signaling pathway in 3T3-L1 adipocyte. Biochem Biophys Res Commun. 2007 ; 364(4) : 1002-8.

17. Hwang JT, Lee MS, Kim HJ, Sung MJ, Kim HY, Kim MS. Antiobesity effect of ginsenoside Rg3 involves the AMPK and
PPAR- $\gamma$ signal pathways. Phytother Res. 2009 ; 23(2) : 262-6.

18. Song YB, An YR, Kim SJ, Park HW, Jung JW, Kyung JS. Lipid metabolic effect of Korean red ginseng extract in mice fed on a high-fat diet. J Sci Food Agric. 2012 ; 92(2) : 388-96.

19. Peters JL, Sutton AJ, Jones DR, Rushton L, Abrams KR. A systematic review of systematic reviews and meta-analyses of animal experiments with guidelines for reporting. J Environ Sci Health B. 2006 ; 41 : 1245-58.

20. Sena ES, Currie GL, McCann SK, Macleod MR, Howells DW. Systematic reviews and meta-analysis of preclinical studies: why perform them and how to appraise them critically. J Cereb Blood Flow Metab. 2014 ; 34(5) : 737-42.

21. Vesterinen HM, Sena ES, Egan KJ, Hirst TC, Churolov L, Currie GL, et al. Meta-analysis of data from animal studies: a practical guide. J Neurosci Methods. 2014 ; 221 : 92-102.

22. Leibel RL. Molecular physiology of weight regulation in mice and humans. Int J Obes. 2008 ; 32 Suppl 7 : S98-108.

23. Schwartz MW, Woods SC, Seeley RJ, Barsh GS, Baskin DG, Leibel RL. Is the energy homeostasis system inherently biased toward weight gain? Diabetes. 2003 ; 52(2) : 232-8.

24. Woods SC. The control of food intake: behavioral versus molecular perspectives. Cell Metab. 2009 ; 9(6) : 489-98.

25. Speakman J, Hambly C, Mitchell S, Król E. Animal models of obesity. Obes Rev. 2007 ; 8(1) : 55-61.

26. McGowan J, Sampson M, Lefebvre C. An evidence based checklist for the peer review of electronic search strategies (PRESS EBC). Evid Based Libr Inf Pract. 2010 ; 5(1) : 149-54.

27. De Vries RBM, Hooijmans CR, Tillema A, Leenaars M, Ritskes-Hoitinga M. A search filter for increasing the retrieval of animal studies in Embase. Lab Anim. 2011 ; 45(4) : 268-70.

28. Hooijmans CR, Tillema A, Leenaars M, Ritskes-Hoitinga M. Enhancing search efficiency by means of a search filter for finding all studies on animal experimentation in PubMed. Lab Anim. $2010 ;$ 44(3) : 170-5.

29. Leenaars M, Hooijmans CR, van Veggel N, ter Riet G, Leeflang M, Hooft L, et al. A step-by-step guide to systematically identify all relevant animal studies. Lab Anim. 2012 ; 46(1) : 24-31.

30. Moher D, Liberati A, Tetzlaff J, Altman DG, PRISMA Group. Preferred reporting items for systematic reviews and metaanalyses: the PRISMA statement. Int J Surg. 2010 ; 8(5) : 336-41.

31. Macleod MR, O'Collins T, Howells DW, Donnan GA. Pooling of animal experimental data reveals influence of study design and publication bias. Stroke. 2004 ; 35(5) : 1203-8.

32. Kilkenny C, Browne W, Cuthill IC, Emerson M, Altman DG, National Centre for the Replacement, Refinement and Reduction of Amimals in Research. Animal research: reporting in vivo experiments: the ARRIVE guidelines. J Cereb Blood Flow Metab. $2011 ; 31(4)$ : 991-3. 
33. Lamontagne F, Briel M, Duffett M, Fox-Robichaud A, Cook DJ, Guyatt $\mathrm{G}$, et al. Systematic review of reviews including animal studies addressing therapeutic interventions for sepsis. Crit Care Med. 2010 ; 38(12) : 2401-8.

34. Higgins JPT, Thompson SG, Deeks JJ, Altman DG. Measuring inconsistency in meta-analyses. BMJ. 2003 ; 327 : 557-60.

35. Egger M, Davey Smith G, Schneider M, Minder C. Bias in meta-analysis detected by a simple, graphical test. BMJ. 1997 ; $315: 629-34$

36. Perel P, Roberts I, Sena E, Wheble P, Briscoe C, Sndercock P, et al. Comparison of treatment effects between animal experiments and clinical trials: systematic review. BMJ. 2007 ; 334 : 197.

37. Hooijmans CR, de Vries RBM, Rovers MM, Gooszen HG, Ritskes-Hoitinga M. The effects of probiotic supplementation on experimental acute pancreatitis: a systematic review and meta-analysis. PLoS One. $2012 ; 7$ : e48811.

38. Hooijmans CR, Ritskes-Hoitinga M. Progress in using systematic reviews of animal studies to improve translational research. PLoS Med. 2013 ; 10 : e1001482.

39. Pound P, Ebrahim S, Sandercock P, Bracken MB, Roberts I. Where is the evidence that animal research benefits humans? BMJ. 2004 ; 328 : 514-7.

40. Howells DW, Sena ES, Macleod MR. Bringing rigour to translational medicine. Nat Rev Neurol. 2014 ; $10: 37-43$.

41. Ritskes-Hoitinga M, Leenaars M, Avey M, Rovers M, Scholten R. Systematic reviews of preclinical animal studies can make significant contributions to health care and more transparent translational medicine. Cochrane Database Syst Rev. 2014 ; 3 : ED000078.

\title{
동물실험에서 인삼의 항비만 효과: 체계적 고찰과 메타분석을 위한 연구 프로토콜
}

\author{
조재흥 · 김고운 · 박혜성 · 윤예지 · 송미연
}

경희대학교 한의과대학 한방재활의학교실

최근 비만이 전 세계적인 문제로 대두되면서 임상 연구의 해석에 필요한 중요 자료를 제시해 줄 수 있는 동물 모델을 이용한 생리학 적 기전 연구에 대한 관심이 높아지고 있다. 인삼은 많은 동물 실험에서 항비만 또는 항당뇨 효과가 보고되었으나 인체의 임상에서 비만을 연구한 논문은 거의 없는 실정이다. 이 연구에서는 신체계측치수와 대사지표를 활용한 동물 모델에서의 인삼의 항비만 효 과의 근거수준을 평가하고자 한다. 전임상 단계에서 비만에 대한 인삼의 효과를 연구한 대조군 연구, 비교 연구를 포함시키고자 한다. 실험적으로 비만을 유도하는 도중 혹은 이후에 인삼을 투여하고, 일차평가변수는 신체계측치수, 이차평가변수는 지방조직 의 무게, 섭취음식의 총량, 대사지표 등을 포함한다. 언어, 출판일 등 특별한 제한 없이 MEDLINE, Embase, PubMed, Web of Science, Scopus를 통해 논문 검색을 시행한다. 본 연구에서의 자료 수집은 개인 정보를 포함하지 않으며, 사생활 침해의 우려가 없으므로 윤리적 승인 대상에서 제외된다. 연구의 전체과정을 수행한 후 연구결과는 연관 저널에 출간하거나 관련 학회에 발표할 예정이다. 본 연구 프로토콜은 the Collaborative Approach to Meta-Analysis and Review of Animal Data from Experimental Studies (CAMARADES) website (http://www.camarades.info)에 등록되었다. 